Article

\title{
Ain't nothing like family - brown bears share their home range with relatives
}

\author{
Astrid Olejarz ${ }^{1,2, *}$, Jouni Aspi ${ }^{1}$, Ilpo Kojola ${ }^{3}$, Vesa Nivala ${ }^{3}$, Alina Niskanen ${ }^{1}$ and Jenni Harmoinen ${ }^{1,4, *}$ \\ 1 Ecology and Genetics Research Unit, PO Box 3000, 90014 University of Oulu, Finland \\ 2 Department of Game Management and Wildlife Biology, Faculty of Forestry and Wood Sciences, Czech \\ University of Life Sciences, Prague, Kamýcká 129, Praha 6 - Suchdol, CZ-165 21, Czech Republic \\ 3 Natural Resources Institute Finland, Ounasjoentie 6, FI-96200, Rovaniemi, Finland \\ 4 Natural Resources Institute Finland, Latokartanonkaari 9, 00790 Helsinki, Finland \\ * Correspondence: olejarz@fld.czu.cz (A.O.); jenni.harmoinen@luke.fi (J.H.)
}

\begin{abstract}
Sociality in animal populations is a continuum, and interactions between conspecifics are meaningful for all vertebrates. Ignorance of social structures can lead to misunderstanding their ecology and, consequently, to unsuccessful species management. Here, we combined genetic and spatial data on radio-collated brown bears (Ursus arctos) to investigate kin-related home range overlap and kin-related centroid distance within central and eastern Finland. We found that the extent of overlap of home ranges was positively linked with relatedness among adult females. A similar positive correlation could be detected between home range centroid distance and relatedness among adult females. Moreover, there were significant differences between the two studied regions: female brown bears in central Finland were more closely related to each other, and the sizes of their home ranges were larger than those in eastern Finland. The smaller home ranges and lower degree of relatedness among bears in eastern Finland might be a result of the substantially higher hunting pressure in the area, combined with immigration of new unrelated individuals from Russia.
\end{abstract}

Keywords: home range overlap; relatedness; kinship; social structure; Ursus arctos

\section{Introduction}

Social structure is a key concept in animal population ecology and should be taken into account in the conservation and management of populations. Active social interactions associated with living in groups may provide higher survival rates through more effective food acquisition strategies and a lower risk of individual predation, among other factors [1]. These types of benefit-based complex social structures are frequently observed in group-living species, such as wolves, horses and whales [2-4]. However, most carnivores live a solitary, noncooperative lifestyle, having very little interaction with conspecifics beyond the mating season [5]. Studying their social structure can be a tedious task, especially for species that are very mobile and live in low densities, rendering data acquisition very challenging. Telemetry tracking has eased the collection of data, and combined with genetic studies, it has henceforth promoted the understanding of such social structures. Three alternative hypotheses have been proposed to explain infrequent social interactions: resource dispersion, land-tenure, and kinship [6]. Each of these hypotheses has merit and can explain the behaviours of solitary animals observed in different ecosystems.

The resource dispersion hypothesis predicts that since resources are heterogeneous in space, the cost of sharing territory with conspecifics is reduced when resources are abundant [7-10]. Accordingly, as long as resources are abundant, even behaviourally solitary species may have overlapping territories. Territorial solitary species are known to aggregate at kills for short time periods [11-13]. The spatial distribution or so-called 'landtenure' hypothesis predicts that solitary carnivores' territorial behaviour is the main 
explanatory factor for the sparse spatial distribution of individuals [11;14;15]. This hypothesis has been shown to accurately capture the social structure of polygynous animals, e.g. in several felid species [6;16]. Males aggressively defend their territories against other males, while female territories might overlap to some degree, but the animals still tend to avoid being concurrently in the overlap regions. The kinship hypothesis predicts that animals tolerate related individuals and even share benefits with them to increase the chance that their genetic material will propagate to the next generations [17]. For this hypothesis to hold, related individuals should be spatially accumulated rather than randomly distributed in the population. Support for this has been found in several species of fish, bears, and woodrats [18-23].

The brown bear (Ursus arctos) is a carnivore that spends most of its time solitary, but on a few occasions, it can get in touch with conspecifics [21]. Social interaction may emerge due to an abundance of food, for example, during the salmon season in Alaska. Brown bear density can be very high along a river with good salmon hunting possibilities [24]. The resource dispersion hypothesis seems to thereby partly explain social interaction among bears. Bears also come into contact during the mating season, when both female and male adult bears tend to roam trying to find mating partners [25].

The mating system of brown bears has been described as promiscuous and polygamous [26]. Typically, female bears mate with three to four males during a breeding season [27]. Males, on the other hand, mate with up to eight females, while some do not obtain any mating [27]. Multiple paternity in a litter has been genetically confirmed and is a frequent phenomenon in brown bears [28]. As both sexes generally mate with several partners, and bears are generally considered nonterritorial animals [30], the land-tenure hypothesis does not seem to explain the social structure in bears. Instead of territory, the living area of a bear is termed its home range. Male home ranges are typically large and overlap with those of several females [21;25]. The size of the home range of female brown bears varies, largely depending on the stage of their breeding cycle. During oestrus, while females are trying to maximize their contacts with males in their search for fit candidates that could father their offspring, their home ranges tend to overlap more with those of other brown bears [30]. A female bear with cubs typically has a smaller home range than one without offspring [31]. The same principle holds true when considering the behavioural differentiation of a single individual over time [32,33]. The primary reason why brown bear mothers tend to restrict their home range size while taking care of their cubs is to avoid contact with male brown bears [34]. Infanticide by males has been observed in Scandinavian brown bears $[28 ; 34]$. It precipitates the recurrence of females' sexual receptivity, and by doing so it improves the males' fitness.

Normally cubs stay with the mother for 1.5-2.5 years [35] and reach sexual maturity at the age of 4-6 years [34]. Adult female black bears (Ursus americanus) have been observed to tolerate home range overlaps with their weaned offspring and even shift their own to make space for their daughters, allowing them to establish their own home range [36]. Based on collar tracking data, young female brown bears have the tendency to migrate only a short distance from their maternal area [37;38]. Male brown bears, on the other hand, were found to disperse from their natal area in $92 \%$ of cases, which is a mechanism for avoiding inbreeding [28;39]. The reason why, unlike males, young females tend to stay close to their mother might be linked to the benefits of sharing territory with kin. It has been shown that in both brown and black bears, individuals with overlapping home ranges are on average more related to each other than individuals with nonoverlapping home ranges $[19 ; 21 ; 22]$. Based on previous studies, the kinship hypothesis seems to best explain the distribution and the social structure of the female brown bears.

Northern European brown bear populations were almost extirpated at the beginning of the twentieth century. At that time, a stable brown bear population existed only in neighbouring Russian territory. In the 1970s and 1980s, the small remnants of the Finnish bear population started to recover [40]. In eastern Finland, the brown bear population increased due to immigration from the larger Russian bear population, forming a genetic 
peripheral segment [40;41]. The brown bear population size has been estimated to be approximately 8,400 individuals in the following regions of Russia: Murmansk, Republic of Karelia, Leningrad, Novgorod and Pskov, in 2010 [42]. In whole European Russia (NorthWestern, Central, Volga, Southern and North-Caucasian federal districts), bear population size has been estimated in 2016 to be approximately 47,100 individuals [43]. In Finland the brown bear population has continued to grow during the recent decades, and the estimated population size is approximately 2,670-2,800 individuals [44]. The stable population from eastern Finland has expanded towards the west into central Finland; thus, bears in these two regions do not differ in their genetic composition [45]. However, the populations are genetically differentiated from the bear population in northern Finland and Scandinavia [45;46], which indicates that the bear population in northern Finland could have been recolonised by a different bear population than the Russian population. Nevertheless, migration rates between Fennoscandian bear populations have recently increased due to management actions [45].

In this study, we compared the social structure of female bears in two regions in Finland: eastern and central Finland. We determined the sizes and overlaps of home ranges and compared the results for the two regions. Furthermore, we estimated the relatedness among individuals using microsatellite data to examine the relevance of the kinship hypothesis in the social structure of Finnish bears and whether there is a difference between the two regions.

\section{Materials and Methods}

\subsection{Study area}

We conducted research in the eastern and central Finland (Figure 1), the regions in which the largest proportion of the brown bear population occurs [44]. The two regions mostly belong to the mid-boreal coniferous vegetation zone [47], where the dominant tree species are coniferous forests, dominated by Scots pine (Pinus sylvestris) and Norway spruce (Picea abies). The topography is relatively flat, and the highest elevations are $<400$ $\mathrm{m}$ A.S.L. Snow cover lasts for about five months on average. As the eastern study region is located next to the Russian border, the influence of the neighbouring bear population is higher. Furthermore, the eastern region has a lower anthropogenic impact due to the almost three times lower human density compared to central Finland [48;49]. In both areas, humans have easy access to bears' home ranges owing to a dense network of forest roads. Contrary to human density, brown bear density is much higher in eastern Finland. In northern Karelia, where all the samples from eastern Finland were collected, the number of brown bears over one year old is over three times higher than that in central Finland [44], even though the regions are similar in size. Due to the much higher bear density in the region, the hunting pressure is of different magnitudes. In 2020, four females were hunted in central Finland, whereas in eastern Finland, 51 were hunted [44]. 


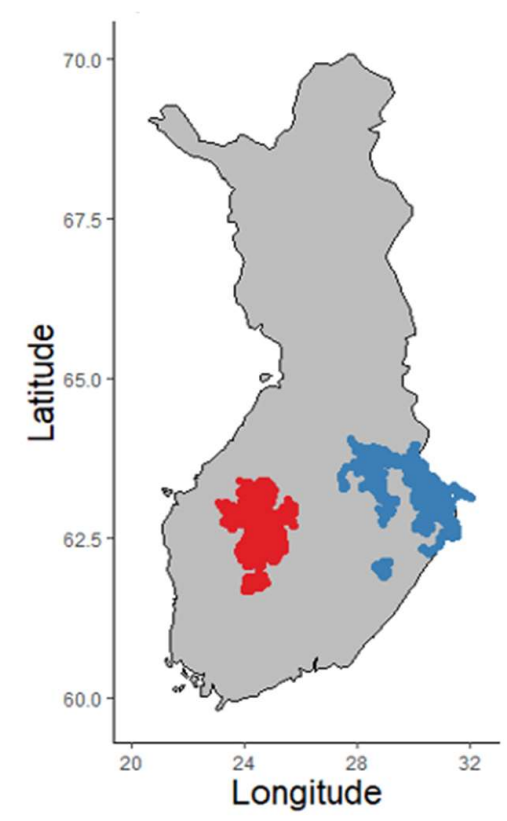

Figure 1. Schematic map of Finland. Two study regions, highlighted with red and blue, illustrate all collected GPS points from 2004-2014.

\subsection{Spatial and genetic data collection}

Spatial data used in this study were obtained via GPS tracking of 53 adult brown bears between the years 2004 and 2014 by the Natural Resource Institute Finland (Luke). The details of capture, handling, anaesthetization were given in a previous study [50]. During radio-collaring, a mouth swab or hair sample was collected from each individual. In the few cases when the collared individual died before the genetic analyses, we used tissue samples instead. The presence of cubs in female brown bears has been reported to Luke for each year via observation. Additionally, we had 65 tissue or hair samples of uncollared brown bears from 2000 and 2014. The tissue samples came from legally shot bears during the bear hunting seasons. The samples were obtained by the University of Oulu from a frozen tissue collection kept by Luke in Taivalkoski, Finland. These samples were included in the study to represent the population more comprehensively in the relatedness estimates. The samples were divided into two geographical groups: eastern and central Finland. Some of the bears in eastern Finland spent part of their time on the Russian side of the border but lived mostly in Finland.

\subsection{Laboratory methods}

According to the manufacturer's instructions, we extracted DNA from saliva $(n=1)$ and tissue $(n=3)$ samples with the DNA Isolation Kit MoBio Ultra Clean®. DNA from the hair samples $(n=49)$ was extracted with the DNA Isolation Kit E.Z.N.A® following the manufacturer's instructions. For genotyping, we used 11 microsatellite primers developed for bears: G1D, G10B, G1A, G10L, MU05, MU09, MU10, MU50, MU51, MU59 and MU15 [52-54]. The same primers have been previously used in Finnish and northern European brown bear studies [41]. Microsatellites were divided into four multiplex groups, and each primer in the group was labelled with different fluorescence dyes: 1) MU09 (PET), MU15 (VIC), G1D (NED); 2) MU05 (PET), G1OL (NED), MU59 (FAM); 3) G10B (NED), MU51 (FAM), G1A (PET); and 4) MU50 (FAM), MU10 (VIC). PCR was performed in $10 \mu \mathrm{l}$ reaction volumes containing QIAGEN Multiplex PCR master mix, $0.2 \mu \mathrm{M}$ of each primer from the corresponding multiplex group and $2 \mu \mathrm{l}$ of template DNA. Initial polymerase activation was performed in $95^{\circ} \mathrm{C}$ for $15 \mathrm{~min}$, followed by 35 cycles of $94{ }^{\circ} \mathrm{C}$ for 30 $\mathrm{s}, 60^{\circ} \mathrm{C}$ for $90 \mathrm{~s}$ and $72{ }^{\circ} \mathrm{C}$ for $30 \mathrm{~s}$ and final elongation at $72{ }^{\circ} \mathrm{C}$ for $5 \mathrm{~min}$. 


\subsection{Genetic analyses}

We estimated the probability of identity for the radio-collared bears $(n=53)$ using the software GenAIEx 6.5 [54]. GenAIEx was also used to estimate inbreeding coefficients for the subpopulations (FIS) [54]. The population structure was analysed via principal component analysis (PCA) using the $R$ environment ( $R$ Core Team 2019) and the package adegenet [56;57]. Allelic richness $\left(A_{R}\right)$ was estimated using FSTAT software [58] and observed and expected heterozygosities were estimated using GENEPOP software [59;60]. Pairwise relatedness was estimated using the $\mathrm{R}$ package related [61]. We simulated 100 pairs of individuals for each degree of relatedness (e.g., parent-offspring, full-sib, unrelated) based on the allele frequency data. Then we removed the unwanted relatedness values and estimated the correlation coefficient between the relatedness values of the simulated individuals of known relatedness. The simulation used four different pairwise relatedness estimators to test the resolution of the dataset. The method of Wang [62] had the highest correlation between observed and expected relatedness values and was thus chosen for further analyses. The method is good with highly polymorphic loci, and it is unbiased even when dealing with small sample sizes. Furthermore, we created a GenePlot [63] for visualizing genetic assignment data by characterizing the distribution of genetic profiles for the two subpopulations. The genetic assignments in GenePlot were calculated out of the 11 microsatellite markers with the saddlepoint approximation method [63]. Statistical analyses were performed in R. To examine whether the average relatedness differed between eastern and central Finland, a two-tailed t-test was performed. To analyse the difference in home range size between the study areas, we used a Mann-Whitney U test. Females with offspring and females without offspring were tested separately.

\subsection{Spatial analysis}

We estimated kernel home ranges using the R package adehabitatHR [64], using the coordinate reference system EUREF_FIN and EPSG:32635-WGS 84/UTM zone 35N + 36N. Variation in the data occurs in the tracking of wildlife over long time periods and in remote areas. Therefore, we calculated the home ranges using the reference bandwidth method, which is relatively unaffected by sample size and the most robust to a variation in sampling intensity [65]. We used a smoothing factor reference bandwidth (h) of $2478.219 \mathrm{~m}$. We defined home ranges as $90 \%$ kernel utilization distribution (UD) isopleths and core home ranges as 50\% kernel UD isopleths. Out of the 53 radio-collared brown bears, 39 individuals sent data regularly. The data from the remaining 14 bears were insufficient, and these individuals were excluded from further analyses. The home range overlaps were calculated with the R package ade4 [66]. Each individual was analysed for overlaps with other individuals for each year separately. Most home range overlaps were detected between 2010 and 2012. The overlapping area was calculated according to Bhattacharyya's affinity method [67]. We estimated centroid distances for each calculated home range using the $\mathrm{R}$ package distances [68]. The Shapiro-Wilk test indicated that the data of home range overlap and centroid distance data were not normally distributed. Thus, we log-transformed the estimated variables to obtain a normal distribution of model residuals. We fitted a linear model for the home range overlap including pairwise relatedness and region as explanatory variables using the $\mathrm{lm}$ function in R. Likewise, we created a linear model for centroid distances including pairwise relatedness and region as explanatory variables. Furthermore, we fitted a linear model including year and age difference as an explanatory factors both for the home range overlap and centroid distance, but dropped it from both models due to the models' worse fit compared to the model that included only home range overlap and region (ANOVA $p<0.05$ ). Since the pairwise comparisons are not independent from each other, we also performed Mantel tests with 9999 permutations [69] separately for bears in eastern Finland and central Finland to examine the correlation between pairwise relatedness and either home range overlap or centroid point distance. 


\section{Results}

\subsection{Genetic diversity}

In total, 53 bear samples were analysed in this study. The mean observed and expected heterozygosities were 0.776 and 0.801 in central Finland $(n=24)$, while the values were 0.795 and 0.810 in eastern Finland, respectively $(n=29)$ (Table 1$)$. The mean expected and observed heterozygosities did not show strong evidence of differences between the regions (two tailed $\mathrm{t}$-test for $\mathrm{HE}_{\mathrm{E}} \mathrm{t}=-0.221 ; \mathrm{df}=16.897 ; p=0.83$ and for Ho: $\mathrm{t}=-0.221$; $\mathrm{df}=$ $16.897 ; p=0.71$ ). The average allelic richness was 8.2 in central Finland and 10.9 in eastern Finland. There was no strong support for differences between the two regions in either inbreeding coefficients (two tailed $\mathrm{t}$-test: $\mathrm{t}=-0.897 ; \mathrm{df}=17.975 ; p=0.3817$ ) or in allelic richness (two tailed $\mathrm{t}$-test: $\mathrm{t}=-1.584 ; \mathrm{df}=19.615 ; p=0.130$ ).

Table 1. Estimated allelic richness ( $\left.\mathrm{A}_{\mathrm{R}}\right)$, observed heterozygosity $(\mathrm{Ho})$, expected heterozygosity $\left(\mathrm{H}_{\mathrm{E}}\right)$ and inbreeding coefficient (FIs) per microsatellite locus based on 53 radiocollared bears divided into two regions: central Finland $(n=24)$ and eastern Finland $(n=29)$.

\begin{tabular}{ccccccccc}
\hline Locus & Central & Ho & HE & FIs & East & Ho & HE & Fis \\
& Ar & & & & Ar & & & \\
\hline MU05 & 6.00 & 0.79 & 0.84 & -0.04 & 6.98 & 0.79 & 0.83 & 0.11 \\
MU09 & 6.00 & 0.79 & 0.86 & -0.11 & 9.92 & 0.79 & 0.82 & 0.16 \\
MU15 & 10.87 & 0.75 & 0.80 & 0.21 & 11.03 & 0.72 & 0.89 & 0.14 \\
G1D & 6.00 & 0.88 & 0.83 & -0.10 & 8.70 & 0.96 & 0.83 & -0.12 \\
G10B & 6.00 & 0.78 & 0.82 & 0.05 & 10.26 & 0.83 & 0.77 & -0.06 \\
MU10 & 5.00 & 0.88 & 0.77 & -0.18 & 6.75 & 0.93 & 0.79 & -0.14 \\
MU50 & 5.00 & 0.50 & 0.61 & -0.17 & 10.04 & 0.63 & 0.52 & 0.10 \\
MU51 & 9.00 & 0.75 & 0.80 & 0.34 & 11.19 & 0.57 & 0.87 & 0.20 \\
MU59 & 15.00 & 0.96 & 0.90 & -0.01 & 21.66 & 0.86 & 0.94 & 0.10 \\
G1A & 14.87 & 0.75 & 0.79 & 0.10 & 15.81 & 0.90 & 0.92 & 0.06 \\
G10L & 5.96 & 0.71 & 0.79 & -0.08 & 7.66 & 0.76 & 0.72 & 0.07 \\
\hline Mean & 8.15 & 0.78 & 0.80 & 0.03 & 10.91 & 0.80 & 0.81 & 0.02 \\
\hline
\end{tabular}

\subsection{Relatedness and genetic structure}

Based on the probability of identity of individuals $\left(\mathrm{PI}=5.6 \mathrm{e}^{-16}\right)$ and siblings (PIsibs $=$ $\left.9.6 \mathrm{e}^{-6}\right)$, the 11 microsatellite markers separated even the closely related individuals well from each other. The mean relatedness among the bears was higher in central Finland (max. likelihood 0.158) than in eastern Finland (max. likelihood 0.054; two tailed $\mathrm{t}$-test: $\mathrm{t}=$ 3.8302; $\mathrm{df}=140.7 ; p<0.05)$. Based on the first $(8.5 \%)$ and second $(7.0 \%)$ axis of Principal Component Analysis, the brown bears in eastern Finland overlap with brown bears from central Finland (Figure 2). However, individuals from eastern Finland showed a higher genetic diversity in comparison to the individuals in central Finland. Based on the GenePlot analysis, many individuals from central Finland had a high probability of also being assigned to the eastern Finland population, with only two individuals having low genotype probability ( $1 \%$ LGPs) of being assigned to the eastern Finland population. On 
average, the brown bears in eastern Finland had lower probabilities of being assigned to the central Finland populations; almost half of the individuals $(44.8 \%, n=13)$ had a very low genotype probability of being assigned there (1\% LGPs). The eastern Finland bears had more diverse LGP values with respect to both populations compared to central Finland bears, reflecting observed higher genetic variation in the eastern population (Figure 3).

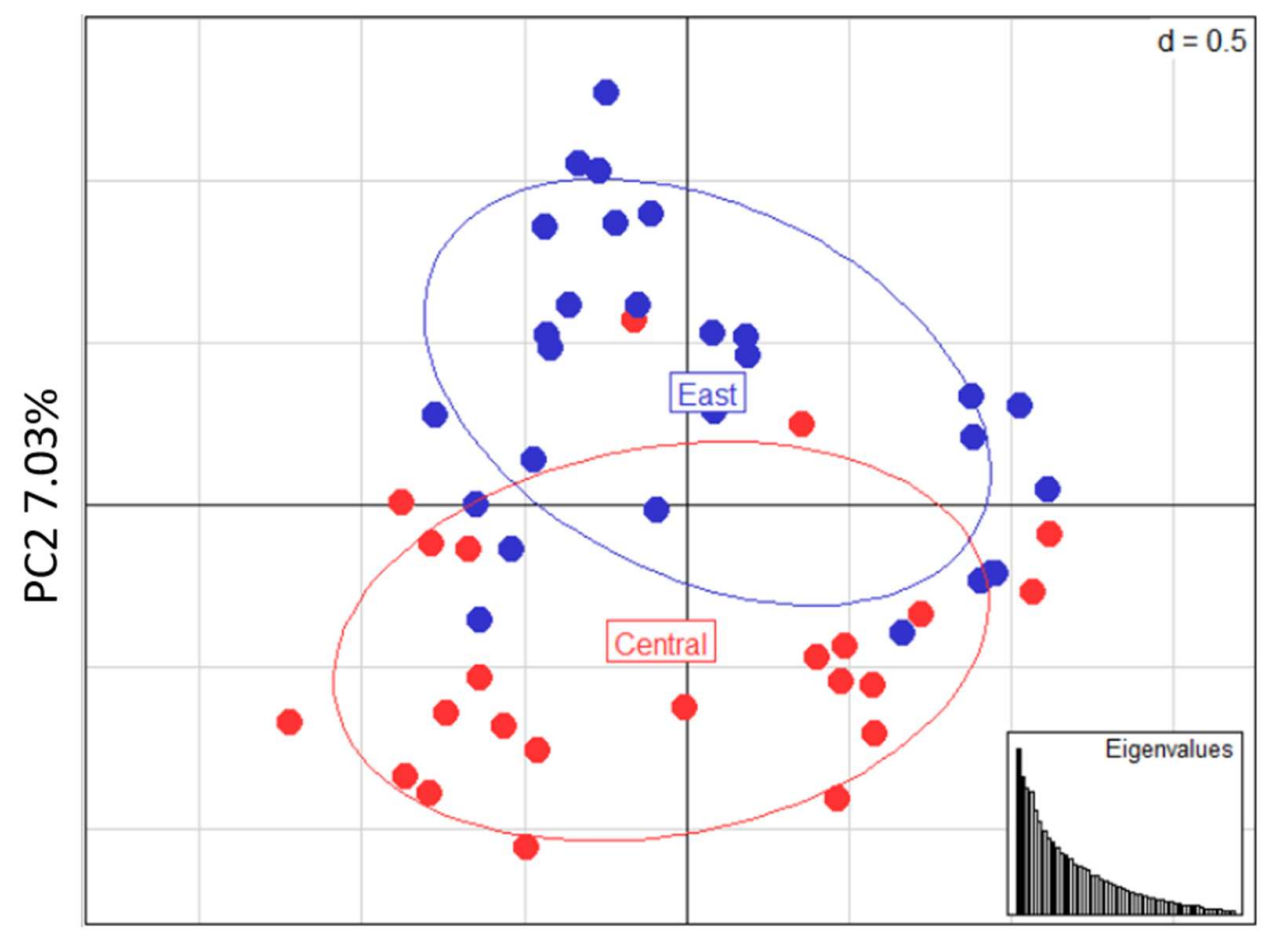

\section{PC1 8.5\%}

Figure 2. Principal Component Analysis (PCA) of the studied brown bears $(n=53)$. The ellipses indicate the genetic distribution of the brown bear individuals from different regions in Finland, showing the first and second axes of the eigenvalues. In the right corner, a scree plot represents the first 50 eigenvalues in the inset. 


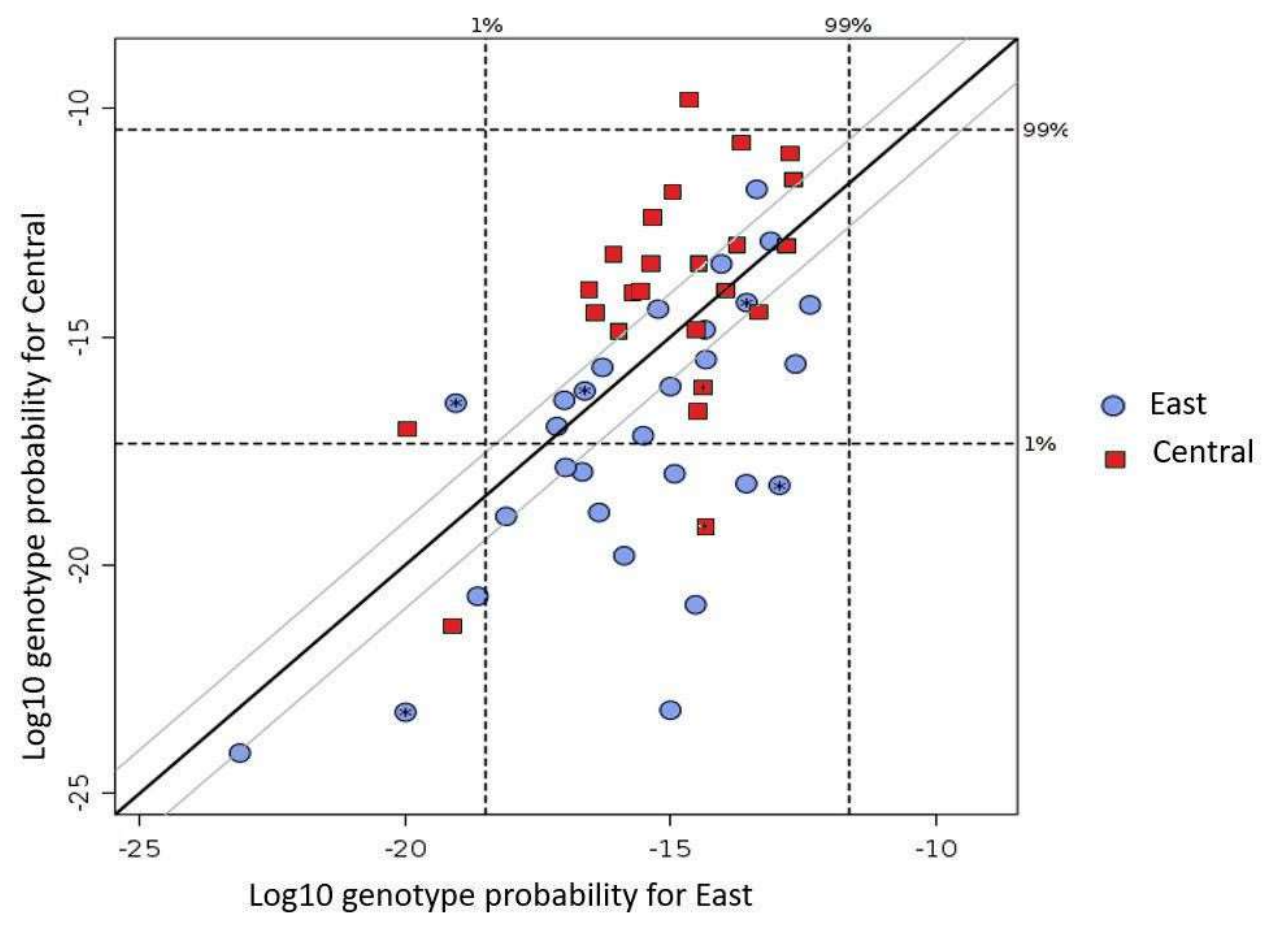

Figure 3. Genetic assignment for the studied brown bears $(n=53)$ using the saddlepoint approximation method implemented in GenePlot. The x-axis shows the posterior log-probability of obtaining each individual's genotype from the eastern Finland population; the y-axis shows the posterior log-probability of obtaining each individual's genotype from the central Finland population. The thick diagonal line shows equal probability with respect to the central and eastern Finland population; the thin diagonal lines indicate that the probability for an individual to belong to one population than for the other is 9 times larger. The vertical dashed lines show the $1 \%$ and $99 \%$ percentile log-genotype probability lines for the eastern Finland population; the horizontal lines show the $1 \%$ and $99 \%$ percentile log-genotype probability lines for the central Finland population. Bears marked with asterisks have missing data at one or more loci.

\subsection{Patterns of space use and their link to relatedness}

We recorded an average of 897 GPS locations per home range for collared brown bears in each study year. Out of the 94 annual home ranges with $90 \%$ kernel home range, only 19 home range estimations had no overlap with other home ranges. According to the GPS tracking results, we found strong evidence that the female brown bear home range sizes differ between the two study areas. Female brown bears had, on average, smaller home ranges in eastern Finland $\left(127 \pm 90.7 \mathrm{~km}^{2}, n=25\right)$ than in central Finland $(862 \pm 490.7$ $\mathrm{km}^{2}, n=56$; Figure 4), strongly supported by a Mann-Whitney $\mathrm{U}$ test $(\mathrm{W}=125 ; p<0.001)$. The kernel home ranges of the females with cubs $\left(491.5 \pm 368.7 \mathrm{~km}^{2}, n=25\right)$ were smaller than the home ranges of the females without cubs $\left(640,1 \pm 677,4 \mathrm{~km}^{2}, n=54\right)$, but the difference was not significant (Mann-Whitney $\mathrm{U}$ test, $\mathrm{W}=603 ; p=0.442$ ). The regression analysis of female brown bears shows that there was a positive association between the pairwise relatedness and the home range overlap with the 90\% kernels $(n=78 ; p=0.004$; Table 2 A; Figure 5). Similarly there was strong association between the pairwise relatedness values and the distances between centroid points of the home ranges $\left(n=354, p=3.07 \mathrm{e}^{-07}\right.$; Table 2 B; Figure 5). Home ranges of female brown bears with high relatedness $(R>0.45)$ overlapped on average $26 \%$ with each other and the average distance between centroid points was $18 \mathrm{~km}$.

However, there was no difference between the two regions in either home range overlap or the distances between the centroid points of home ranges $(p>0.05)$. The observed Mantel correlation between pairwise relatedness and centroid distance was 
positive for central Finland (Mantel $r=0.122, p<0.01$ ) but very weak for eastern Finland (Mantel $\mathrm{r}=0.0521, p=0.133$ ). There was no correlation between pairwise relatedness and home range overlap in either central Finland (Mantel $r=0.050, p=0.094$ ) or eastern Finland (Mantel $\mathrm{r}=-0.117, p=0.691$ ).

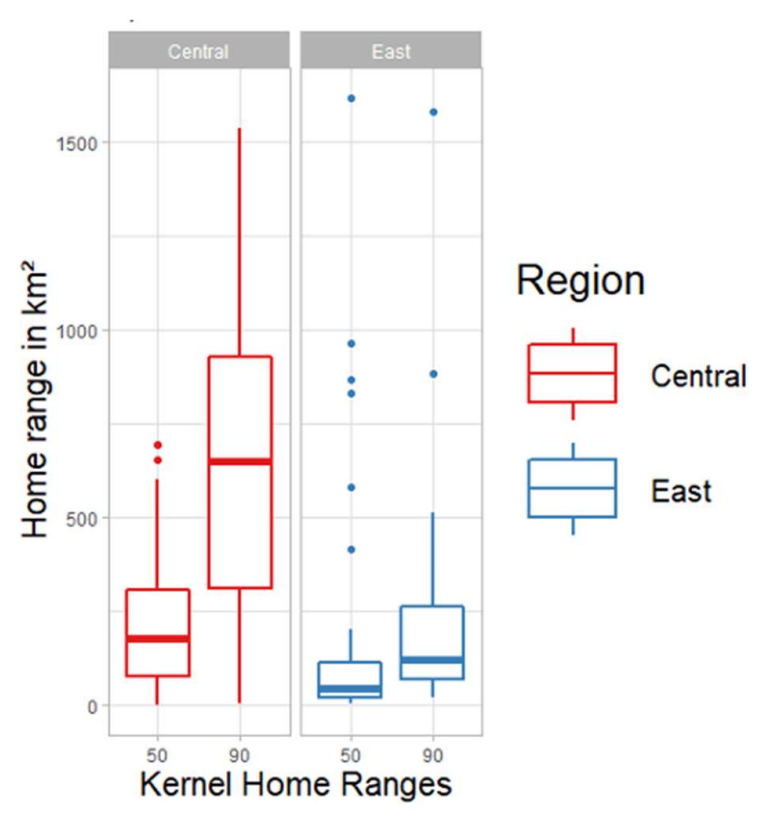

Figure 4. Comparison of home ranges between the Centraland Eastern Finland and between the home range size of $90 \%$ UD isopleths and the core home range size of 50\% UD isopleths.

Table 2. Results of model estimations: A) The effect of pairwise relatedness and region on home range overlap in female brown bears; B) The effect of pairwise relatedness and region on centroid distance of home ranges in female brown bears.

\begin{tabular}{cccc}
\hline & Term & Estimate SE & $P$ \\
\hline A) Home range overlap & (Intercept) & $0.128 \pm 0.016$ & $3.38 \mathrm{e}-11^{* * *}$ \\
& Pairwise relatedness & $0.145 \pm 0.0487$ & $0.004^{* *}$ \\
& Region (eastern Finland) & -0.0310 .047 & 0.502 \\
\hline B) Centroid distance & (Intercept) & 3.8460 .054 & $2 \mathrm{e}-16^{* * *}$ \\
& Pairwise relatedness & -1.0340 .197 & $3.07 \mathrm{e}-07^{* * *}$ \\
& Region (eastern Finland) & -0.0570 .095 & 0.379166667 \\
\hline
\end{tabular}



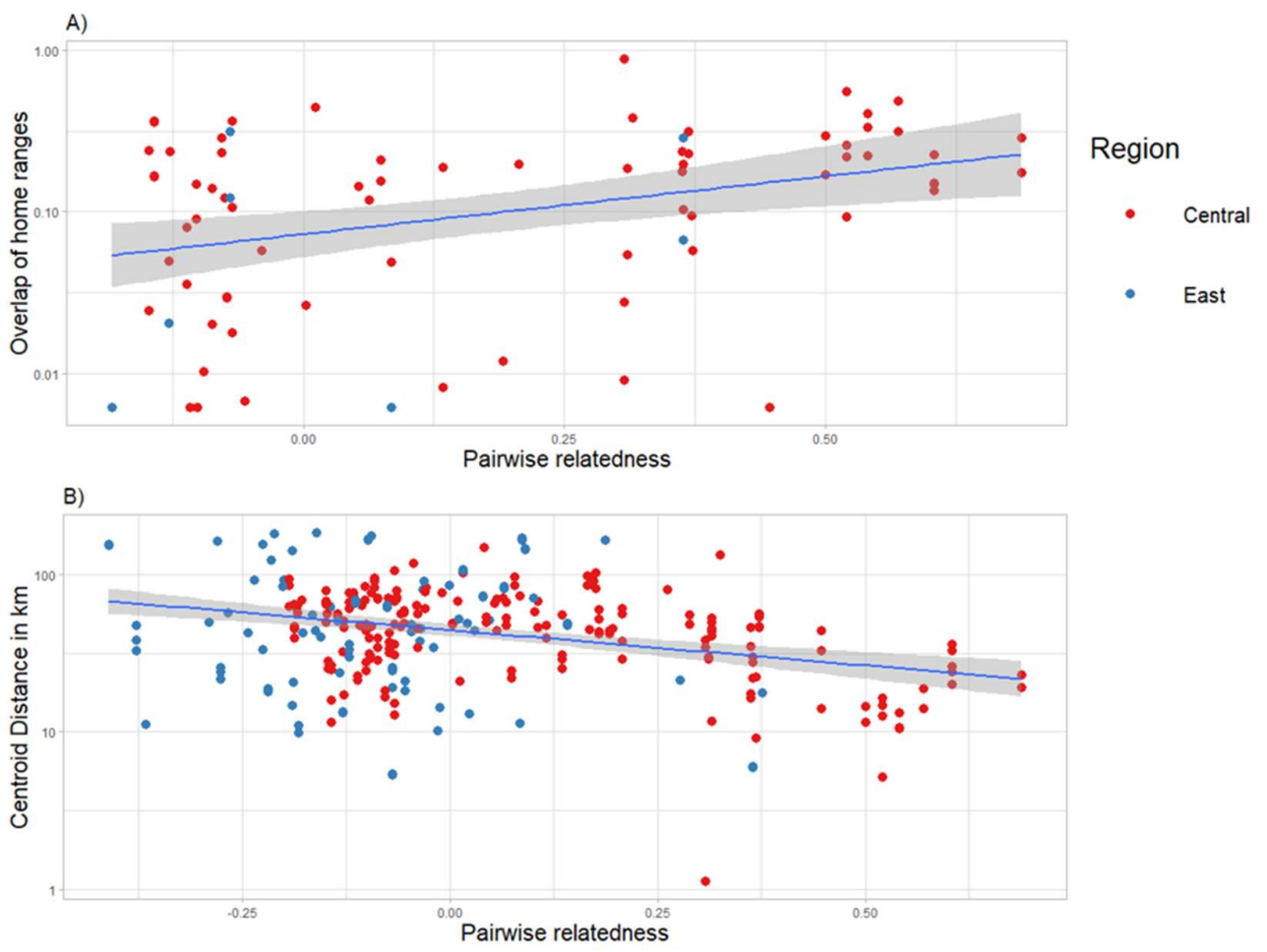

Figure 5. (A) Relationship between the home range overlap and pairwise relatedness of female brown bears in Finland. (B) Relationship between the home range centroid distance in km and pairwise relatedness of female brown bears in Finland. The blue line is the predicted mean effect of pairwise relatedness on the home range overlap, and the shaded grey area is the lower and the upper $95 \%$ confidence limit for the expected values. Dots are pairwise observations.

\section{Discussion}

Kinship seems to be an important factor in determining the social structure of bears in Finland. We found strong evidence for a linear relationship between pairwise relatedness among the individuals and the extent of home range overlap (Figure 5). These findings are similar to findings in other brown bear populations in Scandinavia [21] and black bears in Canada [19]. However, the home range size and the extent of relatedness of female brown bears differed between eastern and central Finland, with the home ranges being smaller and the relatedness among the bears being lower in eastern Finland. Knowing the difference in the home range size between the two regions in Finland is important for management purposes. Average home range sizes of females with cubs are used for estimating the number of litters in each year. The number of litters is in turn used in the census size estimation of brown bears in Finland.

The difference in home range sizes between the two regions can be largely explained by the three times higher bear density in eastern Finland, which has a multifactor impact: there is less available land to establish a home range, a higher risk of encountering infanticidal males, and greater danger of getting hunted in the region [70]. Therefore, keeping the roaming area smaller might be more beneficial than in central Finland. High hunting pressure has also been shown to disrupt structure among matrilines, even though it causes shorter female dispersal distances [71]. Increased population density has also had an adverse impact on home range sizes also in other bear studies [72;73], as well as studies on other species [74-76].

Another factor that could have influenced the difference in the average size of home ranges between the two regions is the possible difference in resource availability between the two areas. A rich habitat has been shown to lead to smaller home ranges in previous studies [77] as individuals are able to acquire sufficient amounts of food from smaller 
home ranges. However, there is no evidence of major differences in habitat quality between these two areas. In both study areas there are several artificial feeding places for bears, and feeding has been shown to affect the behaviour of bears locally in several ways, e.g., individuals using the sites tend to be less mobile than those who do not [78]. Additionally, females with cubs seemed to avoid artificial feeding sites that were visited by adult males [49]. However, as feeding places occur in both areas, they should not have had a systematic impact on the observed differences between the regions. Home range size was not correlated with the food availability index in Scandinavian bears [73].

A comparison of home range sizes in eastern Finland and central Finland to brown bear populations in different countries shows that brown bears in central Finland have one of the largest home ranges; only in North America do home ranges seem to be of similar size. The home ranges of female brown bears in eastern Finland were of similar size to those in Scandinavia, whereas home ranges were clearly smaller in southern Europe and Japan (Table 3).

Table 3. Comparison of home ranges in $\mathrm{km}^{2}$ between two regions in Finland (bold) and other published brown bear populations based on GPS coordinates including the number of individuals $(n)$ and female home range size $(F)$.

\begin{tabular}{cccc}
\hline Population & $n$ & $F$ & Reference \\
\hline North America & 35 & 2577 & {$[77]$} \\
North America (Alaska) & 20 & 356 & {$[79]$} \\
NorthAmerica (Yellowstone) & 21 & 884 & {$[80]$} \\
Japan (Hokkaido) & 3 & 43 & {$[81]$} \\
Croatia & 5 & 58 & {$[82]$} \\
Slovenia & 5 & 53 & {$[83]$} \\
Spain & 1 & 28 & {$[84]$} \\
Scandinavia & 37 & 437 & {$[21]$} \\
Scandinavia (South) & 34 & 217 & {$[34]$} \\
Scandinavia (North) & 18 & 280 & {$[34]$} \\
Finland (Eastern) & 25 & 127 & This study \\
Finland (Central) & 56 & 862 & This study \\
\hline
\end{tabular}

One of the possible explanations for the difference in the level of relatedness among bears in the two regions is spatio-historical: the eastern bear population was founded by Russian individuals, and there has been constant migration pressure from Russia, while the population in central Finland was established by a small number of founders from the eastern population.

Despite the previously mentioned differences, we did not find large differences in the strength of kin-based social structure between the regions; the benefits of sharing a home range with relatives appear to be similar, regardless of the relatedness among the bears being generally much higher in central Finland. Kinship-based social structures emerge when female brown bears establish their home ranges close to their natal area, thereby benefiting from their mother's high-quality home range [78]. The mothers also benefit from living in close contact with their offspring;it increases the probability of their offspring's long-term survival, and the mothers are safer against other dominant females 
who could otherwise dispute the area more aggressively. Dominant females, especially mothers, can suppress other females living close by [29]. If resources are scarce and partially shared among related female brown bears, females tend to have offspring in different years [22]. This suppression caused by dominant females has been reported mostly in large carnivores that live in packs, such as wolves [3]. Dominant females are usually older brown bears, suggesting some connection between age and social organization.

As already shown in a previous study [45], the bears in central Finland are genetically a subset of the eastern Finland population (Figure 3). Migration in brown bears is densitydependent [22]. The high-density population in eastern Finland has more migration pressure towards the lower density population in central Finland than vice versa, as shown in the GenePlot results. It is also known that during 1982-1993, five bears were translocated from eastern Finland to central Finland to establish the local bear population there [85]. In the GenePlot results there were three bears in central Finland and one in eastern Finland, which had a low probability of being assigned to either of the two populations, suggesting that they originally came from outside the study area. The connectivity between the bear populations has recently increased [45], and there has been a constant increase in the population size since the late 1960s [86]. Genetic variation in the study areas was as high as in other bear populations [87-89] and similar to that of other Finnish brown bear studies [41]. The low FIs value for brown bears in Finland implies intensive migration between Finnish and Karelia bear populations [90].

\section{Conclusions}

We show that female brown bears have kinship-based social structures in central and eastern Finland. The home range overlap increases and the distance of the home range centroids decreases as relatedness among the individuals increases. Kin-related spatial structure has also been found in other bear studies [19;21;22]. We also showed that home ranges were smaller in eastern Finland than in central Finland. This may be due to the higher population density in eastern Finland, which causes more conflicts between the bears, e.g., competition foravailable living habitats and infanticide by males. This, combined with higher anthropogenic disturbances through higher hunting pressure and immigration of unrelated individuals from the neighbouring bear population into the region, can break the matriline structure and affect the mobility and sociality of the female brown bears in the area. The difference in the home range size between the regions needs to be taken into account in the census size estimations of the Finnish bear population, as the census size estimate is based on the estimated number of litters per year, in which the average home range sizes of females with cubs from that year are used in the estimates.

Supplementary Materials: The following are available online at www.mdpi.com $/ x x x / s 1$. TableS1: Microsatellite data of radio-collared brown bears and bears used as a reference data in the analyses. TableS2: Spatial data as centroid distances for each radio-collared bear used in the study. TableS3: Spatial data as home range overlaps for each radio-collared bear used in the study.

Author Contributions: Conceptualization, A.O., A.N. and J.H.; methodology, A.O., V.N., A.N. and J.H.; software, A.O., V.N., A.N. and J.H.; validation, A.O., J.A., I.K., A.N. and J.H.; formal analysis, A.O., A.N. and J.H.; investigation, A.O., A.N. and J.H.; resources, J.A., and I.K. data curation, A.O. and I.K; writing-original draft preparation, A.O., J.A., I.K., A.N. and J.H.; writing-review and editing, A.O., J.A., I.K., A.N. and J.H.; visualization, A.O.; supervision, A.N. and J.H.; project administration, A.O., A.N. and J.H.; funding acquisition, A.O., J.A. and I.K. All authors have read and agreed to the published version of the manuscript.

Funding: A.O. was funded by Riistasäätiö and the Societas pro Fauna et Flora Fennica.

Institutional Review Board Statement: Capture, handling, anaesthetizing, collaring and DNA sampling of the bears met the guidelines issued by the Animal Care and Use Committee at the University of Oulu and permits provided by the provincial government of Oulu and the Regional State Administrative Agency (OYEKT-6-99, OLH-01951/Ym-23, ESAVI/3229/04.10.07/2013). 
Data Availability Statement: Data is contained within the article or supplementary material. The data presented in this study are available in Table S1, Table S2 and Table S3.

Conflicts of Interest: The authors declare no conflict of interest. The funders had no role in the design of the study; in the collection, analyses, or interpretation of data; in the writing of the manuscript, or in the decision to publish the results.

\section{References}

1. Whitehead, H. Analysing animal social structure. Anim. Behav. 1997, 53, 1053-1067. https://doi.org/10.1006/anbe.1996.0358.

2. Keiper, R.R. Social Interactions of the Przewalski Horse (Equus Przewalskii Poliakov, 1881) Herd at the Munich Zoo. Appl. Anim. Behav. Sci. 1988, 21, 89-97. https://doi.org/10.1016/0168-1591(88)90102-5.

3. Peterson, R.O.; Jacobs, A.K.; Drummer, T.D.; Mech, L.D.; Smith, D.W. Leadership Behavior in Relation to Dominance and Reproductive Status in Gray Wolves, Canis Lupus. Can. J. Zool. 2002, 80, 1405-1412. https://doi.org/10.1139/z02-124.

4. Gero, S.; Gordon, J.; Whitehead, H. Individualized Social Preferences and Long-Term Social Fidelity between Social Units of Sperm Whales. Anim. Behav. 2015, 102, 15-23. https://doi.org/10.1016/j.anbehav.2015.01.008.

5. Sandell, M. The Mating Tactics and Spacing Patterns of Solitary Carnivores. In Carnivore Behavior, Ecology, and Evolution; Gittleman, J.L., Ed.; Springer US: Boston, MA, 1989; pp. 164-182. ISBN 978-1-4757-4716-4.

6. Elbroch, L.M.; Lendrum, P.E.; Quigley, H.; Caragiulo, A. Spatial Overlap in a Solitary Carnivore: Support for the Land Tenure, Kinship or Resource Dispersion Hypotheses? J. Anim. Ecol. 2016, 85, 487-496. https://doi.org/10.1111/1365-2656.12447.

7. Macdonald, D.W. The Ecology of Carnivore Social Behaviour. Nature 1983, 301, 379-384. https://doi.org/10.1038/301379a0.

8. Johnson, D.D.P.; Kays, R., Blackwell, P.G.; Macdonald, D.W. Does the resource dispersion hypothesis explain group living? Trends Ecol. Evol. 2002, 17, 563-570. https://doi.org/10.1016/S0169-5347(02)02619-8.

9. Wagner, A.; Frank, L.; Creel, S. Spatial grouping in behaviourally solitary striped hyaenas, Hyaena hyaena. Anim. Behav. 2008, 75, 1131-1142. https://doi.org/10.1016/j.anbehav.2007.08.025.

10. Macdonald, D.W.; Johnson, D.D.P. Patchwork Planet: The Resource Dispersion Hypothesis, Society, and the Ecology of Life. J. Zool. 2015, 295, 75-107. https://doi.org/10.1111/jzo.12202.

11. Seidensticker, J.C.; Hornocker, M.G.; Wiles, W.V.; Messick, J.P. Mountain Lion Social Organization in the Idaho Primitive Area. Wildl. Monogr. 1973, 35, 3-60. http://www.jstor.org/stable/3830509.

12. Guilder, J.; Barca, B.; Arroyo-Arce, S.; Gramajo, R.; Salom, R. Jaguars (Panthera Onca) Increase Kill Utilization Rates and Share Prey in Response to Seasonal Fluctuations in Nesting Green Turtle (Chelonia Mydas Mydas) Abundance in Tortuguero National Park, Costa Rica. Mamm. Biol. 2015, 80, 65-72. https://doi.org/10.1016/j.mambio.2014.11.005.

13. Elbroch, L.M.; Quigley, H. Social Interactions in a Solitary Carnivore. Curr. Zool. 2017, 63, 357-362. https://doi.org/10.1093/cz/zow080.

14. Ferreras, P.; Beltrán, J.F.; Aldama, J.J.; Delibes, M. Spatial Organization and Land Tenure System of the Endangered Iberian Lynx (Lynx Pardinus). J. Zool. 1997, 243, 163-189. https://doi.org/10.1111/j.1469-7998.1997.tb05762.x.

15. Diefenbach, D.R.; Hansen, L.A.; Warren, R.J.; Conroy, M.J. Spatial Organization of a Reintroduced Population of Bobcats. J. Mammal. 2006, 87, 394-401. https://doi.org/10.1644/05-MAMM-A-114R1.1.

16. López-Bao, J.V.; Rodríguez, A.; Alés, E. Field Observation of Two Males Following a Female in the Iberian Lynx (Lynx Pardinus) during the Mating Season. Mamm. Biol. 2008, 73, 404-406. https://doi.org/10.1016/j.mambio.2007.10.012.

17. Griffiths, S.W.; Armstrong, J.D. The Benefits of Genetic Diversity Outweigh Those of Kin Association in a Territorial Animal. Proc. Biol. Sci. 2001, 268, 1293-1296, doi:10.1098/rspb.2001.1660.

18. Brown, G.E.; Brown, J.A. Do Kin Always Make Better Neighbours?: The Effects of Territory Quality. Behav. Ecol. Sociobiol. 1993, 33, 225-231. https://doi.org/10.1007/BF02027119.

19. Schenk, A.; Obbard, M.E.; Kovacs, K.M. Genetic Relatedness and Home-Range Overlap among Female Black Bears (Ursus Americanus) in Northern Ontario, Canada. Can. J. Zool. 1998, 76, 1511-1519.

20. Griffiths, S.; Armstrong, J. Kin-Biased Territory Overlap and Food Sharing among Juvenile Atlantic Salmon. J. Anim. Ecol. 2002, 71, 480-486. https://doi.org/10.1046/j.1365-2656.2002.00614.x.

21. Støen, O.-G.; Bellemain, E.; Sæbø, S.; Swenson, J.E. Kin-Related Spatial Structure in Brown Bears Ursus Arctos. Behav. Ecol. Sociobiol. 2005, 59, 191-197. https://doi.org/10.1007/s00265-005-0024-9.

22. Ordiz, A.; Støen, O.-G.; Swenson, J.E.; Kojola, I.; Bischof, R. Distance-Dependent Effect of the Nearest Neighbor: Spatiotemporal Patterns in Brown Bear Reproduction. Ecol. 2008, 89, 3327-3335, doi:10.1890/07-1921.1.

23. Innes, R.J.; McEachern, M.B.; Van Vuren, D.H.; Eadie, J.M.; Kelt, D.A.; Johnson, M.L. Genetic Relatedness and Spatial Associations of Dusky-Footed Woodrats (Neotoma Fuscipes). J. Mammal. 2012, 93, 439-446. https://doi.org/10.1644/11-MAMM-A-171.1.

24. Rode, K.D.; Farley, S.D.; Robbins, C.T. Sexual dimorphism, reproductive strategy, and human activities determine resource use by brown bears. Ecol. 2006, 87, 2636-2646. https://doi.org/10.1890/0012-9658(2006)87[2636:SDRSAH]2.0.CO;2.

25. Dahle, Bj.; Swenson, J.E. Family Breakup in Brown Bears: Are Young Forced to Leave? J. Mammal. 2003, 84, 5. https://doi.org/10.1644/1545-1542(2003)084<0536:FBIBBA>2.0.CO;2.

26. Steyaert, S.M.J.G.; Endrestøl, A.; Hackländer, K.; Swenson, J.E.; Zedrosser, A. The Mating System of the Brown Bear Ursus Arctos: Brown Bear Mating System. Mammal. Review. 2012, 42, 12-34. https://doi.org/10.1111/j.1365-2907.2011.00184.x. 
27. Craighead, L.; Paetkau, D.; Reynolds, H.V.; Vyse, E.R.; Strobeck, C. Microsatellite Analysis of Paternity and Reproduction in Arctic Grizzly Bears. J. Hered. 1995, 86, 255-261. https://doi.org/10.1093/oxfordjournals.jhered.a111578.

28. Bellemain, E.; Swenson, J.E.; Taberlet, P. Mating Strategies in Relation to Sexually Selected Infanticide in a Non-Social Carnivore: The Brown Bear. Ethology 2006, 112, 238-246. https://doi.org/10.1111/j.1439-0310.2006.01152.x.

29. McLellan, B.N.; Hovey, F.W. Natal Dispersal of Grizzly Bears. Can. J. Zool. 2001, 79, 838-844. https://doi.org/10.1139/z01-051.

30. Schwartz, C.C.; Miller, S.D.; Haroldson, M.A. Grizzly bear Ursus arctos. In: Wild mammals of North America: Biology, management, and conservation. 2nd edition. Johns Hopkins University Press, Baltimore, MD, 2003; pp. 556-586. http://pubs.er.usgs.gov/publication/70169862.

31. Bellemain, E.; Zedrosser, A.; Manel, S.; Waits, L.P.; Taberlet, P.; Swenson, J.E. The Dilemma of Female Mate Selection in the Brown Bear, a Species with Sexually Selected Infanticide. Proc. Biol. Sci. 2006, 273, $283-291$. https://doi.org/10.1098/rspb.2005.3331.

32. Glenn, L.P.; Miller, L.H. Seasonal movements of an Alaska Peninsula brown bear population. In C. J. Martinka, and K. L. McArthur, editors. Bears: Their Biology and Management: A Selection of Papers from the 4th International Conference on Bear Research and Management. International Association for Bear Research and Management, Kalispell, Montana, 1980, pp. 307-312.

33. Dahle, B.; Swenson, J.E. Home Ranges in Adult Scandinavian Brown Bears (Ursus Arctos): Effect of Mass, Sex, Reproductive Category, Population Density and Habitat Type. J. Zool. 2003, 260, 329-335. doi:10.1017/S0952836903003753.

34. Dahle, B.; Swenson, J.E. Seasonal Range Size in Relation to Reproductive Strategies in Brown Bears Ursus Arctos. J. Anim. Ecol. 2003, 72, 660-667. https://doi.org/10.1046/j.1365-2656.2003.00737.x.

35. Van de Walle, J.; Pigeon, G.; Zedrosser, A.; Swenson, J.E.; Pelletier, F. Hunting regulation favors slow life histories in a large carnivore. Nat. Commun. 2018, 9, 1100. https://doi.org/10.1038/s41467-018-03506-3.

36. Rogers, L. Effects of Food Supply and Kinship on Social Behavior Movements and Population Growth of Black Bears in Northeastern Minnesota USA. Wildl. Monogr. 1987, 97, 1-72.

37. Støen, O.-G.; Zedrosser, A.; Sæbø, S.; Swenson, J.E. Inversely Density-Dependent Natal Dispersal in Brown Bears Ursus Arctos. Oecologia 2006, 148, 356. https://doi.org/10.1007/s00442-006-0384-5.

38. Kojola, llpo; Danilov, P.I.; Laitala, H.-M.; Belkin, V.A.; Yakimov, A. Brown Bear Population Structure in Core and Periphery : Analysis of Hunting Statistics from Russian Karelia and Finland. Ursus 2007, 17-20. https://www.jstor.org/stable/3872952.

39. Zedrosser, A.; Dahle, B.; Swenson, J.E.; Gerstl, N. Status and Management of the Brown Bear in Europe. Ursus 2001, 12, 9-20. https://www.jstor.org/stable/3873224.

40. Pulliainen, E. Brown Bear Immigration into Finland from the East. Bears: Their Biology and Management 1986, 6, 15-20. https://doi.org/10.2307/3872801.

41. Kopatz, A.; Eiken, H.G.; Hagen, S.B.; Ruokonen, M.; Esparza-Salas, R.; Schregel, J.; Kojola, I.; Smith, M.E.; Wartiainen, I.; Aspholm, P.E.; Wikan, S.; Rykov, A. M.; Makarova, O.; Polikarpova, N.; Tirronen, K. F.; Danilov, P. I.; Aspi, A. Connectivity and Population Subdivision at the Fringe of a Large Brown Bear (Ursus Arctos) Population in North Western Europe. Conserv. Genet. 2012, 13, 681-692. https://doi.org/10.1007/s10592-012-0317-2.

42. Danilov, P.I.; Tirronen, K.F.; Belkin, V.V.; Panchenko, D.V.; Fedorov, F.V. Brown bear and an estimate of its abundance in the European taiga. PetroPress, Petrozavodsk, 2014; pp. 33. ISBN 978-5-8430-0117-9.

43. Kolesnikov, V.V.; Dvornikov, M.G.; Zarubin, B.E.; Makarov, V.A.; Makarova, D.S.; Piminov. V.N.; Pankratov, A.P.; Sinitsyn, A.A.; Skumatov, D.V.; Soloviev, V.A.; Strelnikov, D.P.; Tuzharov, E.S.; Shevnina, M.S.; Utrobina, V.V.; Economov, A.V.; Dolinin, V.V.; Golub, A.M.; Zhukov, A.Yu. Scientifically grounded proposals for the state system for monitoring the resources of the main species of hunting animals in the Russian Federation. FGBNU VNIIOZ, Kirov, Russia, 2017; pp. 37. Available online: http://vniioz-kirov.ru/upload/iblock/f24/f24282455681542b9fe9ff519eabecfd.pdf (accessed 9th October 2021).

44. Heikkinen, S. Karhukanta Suomessa 2020. Luonnonvara- ja biotalouden tutkimus 2020, 20/2021, 15. ISBN:978-952-380-177-6.

45. Kopatz, A.; Kleven, O.; Kojola, I.; Aspi, J.; Norman, A.J.; Spong, G.; Gyllenstrand, N.; Dalén, L.; Fløystad, I.; Hagen, S.B.; Kindberg, J.; Øystein, F. Restoration of Transborder Connectivity for Fennoscandian Brown Bears (Ursus Arctos). Biol. Conserv. 2021, 253, 108936. https://doi.org/10.1016/j.biocon.2020.108936.

46. Kopatz, A.; Eiken, H.G.; Aspi, J.; Kojola, I.; Tobiassen, C.; Tirronen, K.F.; Danilov, P.I.; Hagen, S.B. Admixture and Gene Flow from Russia in the Recovering Northern European Brown Bear (Ursus Arctos). PLoS ONE 2014, 9, e97558. https://doi.org/10.1371/journal.pone.0097558.

47. Ahti, T.; Hämet-Ahti, L.; Jalas, J. Vegetation Zones and Their Sections in Northwestern Europe. Ann. Bot. Fennici 1968, 5, 169211. https://www.jstor.org/stable/23724233.

48. National Land Survey of Finland. Suomen pinta-ala kunnittain 1.1.2021. Available online: https://www.maanmittauslaitos.fi/sites/maanmittauslaitos.fi/files/attachments/2021/02/Vuoden_2021_pinta-alatilasto_kunnat_maakunnat.pdf (accessed 15th April 2021).

49. Statistics Finland, Population. Available online: https://www.tilastokeskus.fi/tup/suoluk/suoluk_vaesto_en.html (accessed 15th April 2021).

50. Penteriani, V.; Lamamy, C.; Kojola, I.; Heikkinen, S.; Bombieri, G.; del Mar Delgado, M. Does Artificial Feeding Affect Large Carnivore Behaviours? The Case Study of Brown Bears in a Hunted and Tourist Exploited Subpopulation. Biol. Conserv. 2021, 254, 108949. https://doi.org/10.1016/j.biocon.2021.108949.

51. Paetkau, D.; Strobeck, C. Microsatellite Analysis of Genetic Variation in Black Bear Populations. Mol. Ecol. $1994,3,489-495$. https://doi.org/10.1111/j.1365-294X.1994.tb00127.x. 
52. Paetkau, D.; Calvert, W.; Stirling, I.; Strobeck, C. Microsatellite Analysis of Population Structure in Canadian Polar Bears. Mol. Ecol. 1995, 4, 347-354. https://doi.org/10.1111/j.1365-294X.1995.tb00227.x.

53. Taberlet, P.; Camarra, J.-J.; Griffin, S.; Uhrès, E.; Hanotte, O.; Waits, L.P.; Dubois-Paganon, C.; Burke, T.; Bouvet, J. Noninvasive Genetic Tracking of the Endangered Pyrenean Brown Bear Population. Mol. Ecol. 1997, 6, 869-876. PMID: 9301075.

54. Peakall, R.; Smouse, P.E. Genalex 6: Genetic Analysis in Excel. Population Genetic Software for Teaching and Research. Mol. Ecol. Notes 2006, 6, 288-295. https://doi.org/10.1093/bioinformatics/bts460.

55. Weir, B.S.; Cockerham, C.C. Estimating F-Statistics for the Analysis of Population Structure. Evol. 1984, 38, 1358-1370. https://doi.org/10.2307/2408641.

56. Jombart, T. Adegenet: A R Package for the Multivariate Analysis of Genetic Markers. Bioinformatics 2008, 24 , 1403-1405. https://doi.org/10.1093/bioinformatics/btn129.

57. Jombart, T.; Ahmed, I. Adegenet 1.3-1: New Tools for the Analysis of Genome-Wide SNP Data. Bioinformatics 2011, 27, 30703071. https://doi.org/10.1093/bioinformatics/btr521.

58. Goudet, J. FSTAT (Version 1.2): A Computer Program to Calculate F-Statistics. J. Hered. 1995, 86, 485-486. https://doi.org/10.1093/oxfordjournals.jhered.a111627.

59. Raymond, M.; Rousset, F. GENEPOP (Version 1.2): Population Genetics Software for Exact Tests and Ecumenicism. J. Hered. 1995, 86, 248-249. https://doi.org/10.1093/oxfordjournals.jhered.a111573.

60. Rousset, F. Genepop'007: A Complete Re-Implementation of the Genepop Software for Windows and Linux. Mol. Ecol. Resour. 2008, 8, 103-106. https://doi.org/10.1111/j.1471-8286.2007.01931.x.

61. Pew, J.; Muir, P.H.; Wang, J.; Frasier, T.R. Related: An R Package for Analysing Pairwise Relatedness from Codominant Molecular Markers. Mol. Ecol. Resour. 2015, 15, 557-561. https://doi.org/10.1111/1755-0998.12323.

62. Wang, J. An Estimator for Pairwise Relatedness Using Molecular Markers. Genetics 2002, 160, 1203-1215.

63. McMillan, L.F.; Fewster, R.M. Visualizations for Genetic Assignment Analyses Using the Saddlepoint Approximation Method. Biometrics 2017, 73, 1029-1041. https://doi.org/10.1111/biom.12667.

64. Calenge, C. The Package "Adehabitat" for the R Software: A Tool for the Analysis of Space and Habitat Use by Animals. Ecol. Modell. 2006, 197, 516-519. https://doi.org/10.1016/j.ecolmodel.2006.03.017.

65. Bauder, J.M.; Breininger, D.R.; Bolt, M.R.; Legare, M.L.; Jenkins, C.L.; McGarigal, K. The Role of the Bandwidth Matrix in Influencing Kernel Home Range Estimates for Snakes Using VHF Telemetry Data. Wildl. Res. 2015, 42, $437-453$. https://doi.org/10.1071/WR14233.

66. Dray, S.; Dufour, A.-B. The Ade4 Package: Implementing the Duality Diagram for Ecologists. J. Stat. Softw. 2007, 22, 1-20. https://doi.org/10.18637/jss.v022.i04.

67. Fieberg, J.; Kochanny, C.O. Quantifying Home-Range Overlap: The Importance of the Utilization Distribution. J. Wildl. Manag. 2005, 69. https://doi.org/10.2193/0022-541X(2005)69[1346:QHOTIO]2.0.CO;2.

68. Savje, F. Distances: Tools for Distance Metrics Version 0.1.8 from CRAN. Available online: https://rdrr.io/cran/distances/ (accessed 5th July 2021).

69. Franckowiak, R.P.; Panasci, M.; Jarvis, K.J.; Acuña-Rodriguez, I.S.; Landguth, E.L.; Fortin, M.-J.; Wagner, H.H. Model Selection with Multiple Regression on Distance Matrices Leads to Incorrect Inferences. PLOS ONE 2017, 12, e0175194. https://doi.org/10.1371/journal.pone.0175194.

70. Kojola, I.; Hallikainen, V.; Heikkinen, S.; Nivala, V. Inadvertent Shooting of Brown Bear Cubs in Finland: What Can Managers Do to Reduce It? Wildlife Biol. 2021, 2021, wlb.00773. https://doi.org/10.2981/wlb.00773.

71. Frank, S.C.; Pelletier, F.; Kopatz, A.; Bourret, A.; Garant, D.; Swenson, J.E.; Eiken, H.G.; Hagen, S.B.; Zedrosser, A. Harvest is associated with the disruption of social and fine-scale genetic structure among matrilines of a solitary large carnivore. Evol Appl. 2021, 14, 1023-1035. https://doi.org/10.1111/eva.13178.

72. Dahle, B.; Swenson, J.E. Seasonal range size in relation to reproductive strategies in brown bears Ursus arctos. J. Anim. Ecol. 2003, 72: 660-667. https://doi.org/10.1046/j.1365-2656.2003.00737.x

73. Dahle, B.; Støen, O.-G.; Swenson, J.E. Factors Influencing Home-Range Size in Subadult Brown Bears. J. Mammal. 2006; 87: 859865. https://doi.org/10.1644/05-MAMM-A-352R1.1.

74. Vincent, J.P.; Bideau, E.; Hewison, A.J.M.; Angibault, J.M. The influence of increasing body weight, kid production, home range and winter grouping in roe deer. J. Zool. 1995, 236, 371-382. https://doi.org/10.1111/j.1469-7998.1995.tb02719.x.

75. Lopez, R. R.; Harveson, P. M.; Peterson, M.N.; Silvy, N. H.; Frank, P. A. From the Field: Changes in ranges of Florida Key deerdoes population density matter? Wildl. Soc. 2005, 33, 343-348. https://www.jstor.org/stable/3784875.

76. Kiefer S. J.; Weckerly F. W. Population density and body weight influences on home range size of feral hogs. Calif. Fish Game 2005, 91, 136-142.

77. Mcloughlin, P.D.; Ferguson, S.H.; Messier, F. Intraspecific Variation in Home Range Overlap with Habitat Quality: A Comparison among Brown Bear Populations. Evolutionary Ecology 2000, 14, 39-60. https://doi.org/10.1023/A:1011019031766.

78. Ramos-Fernández, G.; Boyer, D.; Gómez, V.P. A Complex Social Structure with Fission-Fusion Properties Can Emerge from a Simple Foraging Model. Behav Ecol Sociobiol 2006, 60, 536-549. https://doi.org/10.1007/s00265-006-0197-x.

79. Collins, G. H.; Kovach, S. D.; Hinkes, M. T. Home range and movements of female brown bears in southwestern Alaska. Ursus 2005, 16, 181-189. http://www.jstor.org/stable/3873029.

80. Blanchard, B. M.; Knight, R. R. Movements of yellowstone grizzly bears. Biol. Conserv. 1991, 58, 41-67. https://doi.org/10.1016/0006-3207(91)90044-A. 
81. Sato, Y.; Kobayashi, Y.; Urata, T.; Takatsuki, S. Home range and habitat use of female brown bear (Ursus arctos) in Urahoro, eastern Hokkaido, Japan. Mammal Study 2008, 33, 99-109. https://doi.org/10.3106/1348-6160(2008)33[99:HRAHUO]2.0.CO;2.

82. Huber, D.; Roth, H. U. Movements of European brown bears in Croatia. Acta Theriol. 1993, 38, 151-159.

83. Kaczensky, P.; Knauer, F.; Krze, B.; Jonozovic, M.; Adamic, M.; Gossow, H. The impact of high speed, high volume traffic axes on brown bears in Slovenia. Biol. Conserv. 2003, 111, 191-204. https://doi.org/10.1016/S0006-3207(02)00273-2.

84. Penteriani, V.; Delgado, M.M.; López-Bao, J.V.; García, P.V.; Monrós, J.S.; Álvarez, E.V.; Corominas, T.S.; Vázquez, V.M. Patterns of movement of released female brown bears in the Cantabrian Mountains, northwestern Spain. Ursus 2017, 28, 165-170. https://www.jstor.org/stable/44751706.

85. Nyholm, E.S. Petosiirrot - riistantutkimuksen vaatimaton kokeilu. (Translocation of large carnivores). Metsästäjä 1995, 44, 1214.

86. Kojola, I.; Heikkinen, S. The Structure of the Expanded Brown Bear Population at the Edge of the Finnish Range. 2006, 43, 258262. https://www.jstor.org/stable/23736871.

87. Waits, L.; Taberlet, P.; Swenson, J.E.; Sandegren, F.; Franzén, R. Nuclear DNA Microsatellite Analysis of Genetic Diversity and Gene Flow in the Scandinavian Brown Bear (Ursus Arctos). Molecular Ecology 2000, 9, 421-431. https://doi.org/10.1046/j.1365294x.2000.00892.x.

88. Zachos, F.E.; Otto, M.; Unici, R.; Lorenzini, R.; Hartl, G.B. Evidence of a Phylogeographic Break in the Romanian Brown Bear (Ursus Arctos) Population from the Carpathians. Mammalian Biology 2008, 73, 93-101. https://doi.org/10.1016/j.mambio.2007.02.007.

89. Straka, M.; Paule, L.; Ionescu, O.; Štofík, J.; Adamec, M. Microsatellite Diversity and Structure of Carpathian Brown Bears (Ursus Arctos): Consequences of Human Caused Fragmentation. Conserv Genet 2012, 13, 153-164. https://doi.org/10.1007/s10592-0110271-4.

90. Hagen, S.B.; Kopatz, A.; Aspi, J.; Kojola, I.; Eiken, H.G. Evidence of Rapid Change in Genetic Structure and Diversity during Range Expansion in a Recovering Large Terrestrial Carnivore. Proc. R. Soc. B 2015, $282,20150092$. https://doi.org/10.1098/rspb.2015.0092. 